\title{
Textual Metaphor from the Non-Finite Clausal Perspective
}

\author{
Qingshun He \\ Guangdong University of Foreign Studies, Guangzhou, China \\ Email: markman1998@163.com
}

Received May $26^{\text {th }}$, 2013; revised July $1^{\text {st }}$, 2013; accepted July $9^{\text {th }}, 2013$

\begin{abstract}
Copyright ( 2013 Qingshun He. This is an open access article distributed under the Creative Commons Attribution License, which permits unrestricted use, distribution, and reproduction in any medium, provided the original work is properly cited.
\end{abstract}

\begin{abstract}
Grammatical metaphor in the Hallidayan sense only comprises ideational and interpersonal metaphors, while Martin and others propose the inclusion of textual metaphor. Based on metafunctions of Systemic Functional Linguistics, this paper analyzes the current discussions of textual metaphor, pointing out that some textual metaphors by Martin and others are in essence representations of ideational and interpersonal metaphors in text, and some are not in accordance with the principles of grammatical metaphor. Four types of textual metaphor with double functions are proposed from the perspective of non-finite clause relators; they are (1) elaborative non-finite clauses, (2) extensive and enhancing non-finite clauses without relators, (3) extensive and enhancing non-finite clauses with prepositions as relators, and (4) enhancing non-finite clauses with prepositionalized non-finite verbs.
\end{abstract}

Keywords: Grammatical Metaphor; Textual Metaphor; Double Functions; Non-Finite Clause; Relator

\section{Introduction}

Grammatical metaphor proposed by Halliday $(1985 ; 1994)$ and Matthiessen (1999; 2004) includes only ideational metaphor and interpersonal metaphor. This propels people to think of the inclusion of textual metaphor in grammatical metaphor. Some systemisists around the world have been trying to carry out research on textual metaphor from various perspectives. However, Halliday himself has never accepted the existence of textual metaphor, and only talked about the textual effect of ideational metaphor (Halliday \& Matthiessen, 2004: p. 642). Based on the concept of grammatical metaphor in the Hallidayan sense, we will analyze the existing researches on textual metaphor, point out their inadequacies, and then investigate textual metaphor from the non-finite clausal perspective.

\section{A Sketch of Grammatical Metaphor}

According to SFL, any given semantic configuration can be realized in a congruent form or various incongruent or metaphorical forms. Congruent forms are recognized as "the typical ways of saying things” (Halliday, 1994: p. 343), and they are "closer to the state of affairs in the external world" (Thompson, 1996: p. 164), while the metaphorical forms are glossed as "not expressed through the most typical (and highly coded) form of representation" (Halliday, 1978: p. 180) , Thus, Halliday proposed the concept of grammatical metaphor, referring to "the expression of a meaning through a lexicogrammatical form which originally evolved to express a different kind of meaning” (Thompson, 1996: p. 165) and "a rea1ignment between a pair of strata: a remapping of the semantics on to the lexicogrammar” (Halliday, 1998: p. 192).

Halliday classifies grammatical metaphor into two subcategories: ideational metaphor and interpersonal metaphor. "The ideational metaphor is metaphor of transitivity and the inter- personal metaphor is metaphor of mood and modality" (Halliday, 1994: p. 343). Let's take (1) as an example:

(1) a. They shredded the documents before they departed for the airport.

b. Their shredding of the documents preceded their departure for the airport.

Here the clauses they shredded the documents and they departed for the airport in (1a) are both rankshifted into nominal groups their shredding of the documents and their departure for the airport in (1b), and the conjunction before is verbalized into preceded. In the process of nominalization and verbalization, other lexicogrammatical items are also transcategorized correspondently, i.e., nominal group they functioning as Thing into adjective their functioning as Possessive Deictic, nominal group the documents functioning as Thing into nominal group the documents functioning as Qualifier, and prepositional phrase for the airport functioning as Location into prepositional phrase for the airport functioning as Qualifier. In other words, ideational metaphors are realized through nominalization, verbalization and transcategorization.

Interpersonal function is realized in the system of modality and the system of mood, in both of which interpersonal metaphor can occur. Halliday (1994: p. 89) distinguishes four types of modality: probability, usuality, obligation and inclination. Each type of modality is realized in four semantic domains: subjective, objective, implicit and explicit. Metaphor of modality occurs when "the speaker's opinion regarding the probability that his observation is valid is coded not as a modal element within the clause, which would be its congruent realization, but as a separate, projecting clause in a hypotactic clause complex" (Halliday, 1994: p. 354). See (2) - (4):

(2) a. Mary will know.

b. I think that Mary knows.

(3) a. Fred usually sits quite quiet. 
b. It's usual for Fred to sit quite quiet.

(4) a. John is supposed to go.

b. It's expected that John goes.

Examples (2), (3) and (4) are probability, usuality and obligation types of modality respectively. Modalities in (2a), (3a) and (4a) are realized by modal elements within the clauses, and those in (2b), (3b) and (4b) by projecting clauses in hypotactic clause complexes. Therefore, (2b), (3b) and (4b) are interpersonal metaphors.

The speech roles in exchange are giving and demanding, and the commodity exchanged are goods-and-services or information. "These two variables, when taken together, define the four primary speech functions of offer, command, statement and question" (Halliday, 1994: p. 69). The four speech functions are expressed by mood, and the speaker can select different mood types, i.e., declarative, interrogative and imperative. The metaphor of mood occurs when the correspondence between speech functions and mood types shifts. For example:

(5) a. I would do my homework first if I were you.

b. Do your homework first!

The declarative type of mood in (5a) metaphorically realizes the speech function of command, the congruent realization of which is (5b).

\section{Existing Researches on Textual Metaphor}

Halliday has never mentioned the concept of textual metaphor. Therefore, "it is debatable whether the label 'textual metaphor' is really justified” (Thompson, 1996: p. 176). Systemicists like Martin (1992, 1993), Thompson (1996), Hu (1996) and Liu (2002, 2003) believe that "textual metaphor" should be included in the study of grammatical metaphor since the three metafunctions of SFL are intertwined. Martin is the first systemicist proposing textual metaphor. In Martin's thinking, certain discourse elements organize text rather than field, which include meta-message relation, text reference, negotiating text and internal conjunction, all of which are text-organizing pro-forms (Martin, 1992: pp. 416-417). For example:

(6) a. I think governments are necessary at different levels for a number of reasons.

b. "Curtsey while you're thinking what to say. It saves time." Alice wondered a little at this, but she was too much in awe of the Queen to disbelieve it.

c. Next, he inserted the key into the lock.

d. Next, he was incapable of inserting the key into the lock.

e. Let me begin by pointing out that the Federal Government fixes up problems that occur in the community.

In (6a), the meta-message a number of reasons is the nominalization of the logico-semantic relation of reason, functioning to organize the text, hence textual metaphor. In (6b), the second pronoun it is a discourse anaphora, referring back to a fact, concept or expression rather than a specific thing, hence also textual metaphor. In (6c), next is part of the discourse content, functioning as external reality. In (6d), next represents the speaker's choice of conversation roles and rhetoric devices, his attitude and judgment, functioning as internal conjunction. This kind of linking words realizing internal conjunction is textual metaphor. In (6e), the negotiation structure Let me begin in dialogue is used in monologue as internal interpretation, hence textual metaphor.

Subsequently, in his work coauthored with Halliday, Martin (1993: pp. 241-243) further groups textual metaphor into meta- phorical Themes and metaphorical News, as in Examples (7) and (8):

(7) a. Between 1937 and 1945 the value of industrial production almost doubled.

b. This increase was faster than otherwise would have occurred.

(8) a. Probably that pudding never will be cooked.

b. I don't think that pudding ever will be cooked.

According to Martin (1993), the clausal Rheme the value of industrial production almost doubled in (7a) is nominalized as phrasal/group Theme This increase in (7b), forming metaphorical Theme, hence textual metaphor. The adverbial interpersonal Theme Probably in (8a) is transcategorized as clausal interpersonal Theme I don't think in (8b), hence textual Metaphor. If such clausal News as Australia's scientific and research capabilities were inadequate in (9a) is transferred into a nominal group inadequacies in Australia's scientific and research capabilities in (9b), metaphorical News occurs. For example:

(9) a. The war had also revealed that Australia's scientific and research capabilities were inadequate.

b. The war had also revealed inadequacies in Australia's scientific and research capabilities.

Thompson (1996: p. 176) includes textual metaphor in the category of grammatical metaphor. According to Thompson, two types of thematic structure, i.e., thematic equatives and predicated Themes, are textual metaphors because both need double transitivity analyses. Thompson (1996) does not mention information metaphor, but Liu (2003) argues that in cleft sentences or pseudo cleft sentences where the new information is placed at the beginning of a sentence, or in sentences where phonological or graphological means such as contrastive stresses, italics or uppercase letters etc. are used to highlight relevant information, metaphorical News occurs. He also points out that marked Themes function to foreground emphases, highlights or cohesion within texts, hence metaphorical Themes.

Apart from these, Lassen (2003a: p. 43; 2003b: p. 283) discusses the textual effects of grammatical metaphor, proposing five types of textual metaphor based on the structural and non structural organizations of text, i.e., compound nouns, passive voice, reference, non-finite clause and ellipsis, and classifies textual metaphor into syntagmatic and paradigmatic metaphors. See Lassen's examples in (10) - (14).

(10) a. Straw walker rear shaft.

b. (the) rear shaft (which is) (on the) walker (which moves the) straw.

(11) a. The grain is moved to the front of the top sieve.

b. (A mechanism) moves the grain to the front of the top sieve.

(12) Connect (the) pipes to (the) cylinder.

(13) a. Operate the valve, checking for continuous flow.

b. Operate the valve and check for continuous flow.

c. Operate the valve while (you) check for continuous flow.

(14) Cleaning shoe drive belt (is) slipping.

According to Lassen (2003), Target straw in (10b) changes into Classifier in (10a), and Actor and Circumstance walker into Thing; active Process in (11b) changes into passive Process in (11a), Actor a mechanism into Agent, and Aim the grain into Medium. Therefore, (10a) and (11a) are syntagmatic textual metaphors. The omission of the definite article the in (12) and that of the is in (14) are the result of systematic choices. (13a) has two possible interpretations, i.e., (13b) and (13c). Therefore, 
(12), (13a) and (14) are paradigmatic textual metaphors.

\section{Inadequacies of the Research on Textual Metaphor}

According to SFL, "language evolved, in the human species, in two complementary functions: construing experience, and enacting social processes” (Halliday \& Matthiessen, 1999: p. xi). The ideational metafunction is a way of knowing the world and construing experiences, and is realized by the system of transitivity. In ideational metafunction, grammatical metaphor is realized as rankshift through nominalizing Process into Actor or Circumstance. Interpersonal metafunction is realized by the system of Mood and that of Modality. In interpersonal metafunction, grammatical metaphor is realized through transcategories among categories of Mood and those among categories of Modality. "The text base provides the resources that enable the speaker to produce contextualized discourse and to guide the listener in interpreting it" (Halliday and Matthiessen, 1999: p. 12), and so "it is a second-order mode of meaning" (ibid, p. 398). “'Metaphor' in general is intrinsically a 'second-order' phenomenon in language" (Taverniers, 2006), that is, a grammatical structure is substituted for by another grammatical structure, which leads to the occurrence of an extra meaning. For example, (15a) is a clause of mental process, which is rankshifted as what you want and is identified with this, and is realigned as a relational clause of the identity type (15b), forming a thematic equative, hence ideational metaphor.

(15) a. You want this.

\begin{tabular}{ccc}
\hline You & want & this \\
\hline Senser & Process & Phenomenon \\
\hline
\end{tabular}

b. What you want is this.

\begin{tabular}{ccc}
\hline What you want & is & this \\
\hline Identifier & Process & Identified \\
\hline
\end{tabular}

Similar analysis also functions in predicated Themes. For example:

(16) a. We have learned how to use it.

\begin{tabular}{ccc}
\hline We & have learned & how to use it \\
\hline Carrier & Process & Attribute \\
\hline
\end{tabular}

b. It is we who have learned how to use it.

\begin{tabular}{cccc}
\hline It & is & we & who have learned how to use it \\
\hline & Process & Identifier \\
& Identified \\
\hline
\end{tabular}

According to Halliday and Matthiessen (1999: p. 242), grammatical metaphor is the result of rankshift or transcategorization. "The grammatical metaphor thus shifts both the rank and the class” (Halliday, 1998: p. 40). However, metaphorical Themes and metaphorical News proposed by Martin (1993) are not the result of rankshift or transcategorization in the system of Theme or in the system of information; they are descriptions of ideational metaphor from different perspectives. For example, according to Martin (1993), the clausal Rheme the value of industrial production almost doubled in (7a) is nominalized into phrasal/group Theme This increase in (7b), resulting in the occurrence of ideational metaphor in (7b). From the perspective of textual metafunction, This increase in (7b) is the unmarked Theme. In the system of information, it acts as the Given information, and in the system of cohesion, it functions as reference, hence no grammatical metaphor occurring in textual metafunction. The adverbial interpersonal Theme Probably in (8a) is transferred into the clausal Theme I don't think in (8b) from implicit objective category to explicit subjective category, hence metaphor of Modality occurring. However, adverbial interpersonal Theme and clausal interpersonal Theme are both unmarked Themes, so the clausal interpersonal Theme is not the necessary condition to produce textual metaphor. Similarly, for example, the nominalization from clausal New information Australia's scientific and research capabilities were inadequate in (9a) into phrasal/group New information inadequacies in Australia's scientific and research capabilities in (9b) is also ideational metaphor, rather than textual metaphor.

Although Huang (2009) also discusses textual metaphor, he does not agree that thematic equatives and predicated Themes are textual metaphors. According to Huang (2002), metaphoric Themes or thematic metaphors are actually ideational metaphors appearing in text.

In addition, changing the thematic and informational structures has the effect of rhetorical or textual emphases. However, marked Thematic structures or marked informational structures are not grammatical metaphors resulting from rankshift or transcategorization. "Grammatical metaphor can be considered as a marked form” (Goatly, 1996). However, "when we say markedness is relevant to metaphor, we do not mean that markedness is itself grammatical metaphor” (Fan, 2001: p. 27). In fact, incongruence and markedness are not the same thing, and in specific contexts, metaphoric form may also be unmarked (Ravelli, 2003). For example, in the system of polarity, positive form is unmarked, and negative form, marked; and in the system of tense, present and past tenses are unmarked, and future tense, marked (Halliday and James, 2005). However, we can not say that negative form and future tense are grammatical metaphors.

Ravelli (2003) does not accept metaphor of cohesion proposed by Martin. According to Ravelli (2003), if the items used to organize texts are grammatical metaphor, abstract nouns such as fact are also grammatical metaphors. Abstract nouns can be called “'meta-comments' rather than grammatical metaphor” (Derewianka, 2003). Interestingly, Martin (1997) also clearly distinguishes abstract Things from grammatical metaphor, and puts that abstract nouns like fact are not at all grammatical metaphors.

Since grammatical metaphor is looked at "as variation in the expression of a given meaning” (Halliday, 1994: p. 342) rather than as variation in the function of a given expression of internal cohesion and external cohesion, then textual metaphor proposed by Martin (1992) is to be reconsidered. In fact, the metaphors of cohesion proposed by Martin (1992) should be understood as various grammatical functions of a given expression. This does not meet the conditions for creating grammati- 
cal metaphors, hence not textual metaphor.

The change of Target straw in (10b) into Classifier in (10a) takes place at the semantic level, while the change of grammatical metaphor takes place at the lexico-grammatical level. In this sense, the compound noun in (10a) is not the metaphoric form of (10b). In addition, a nominal group itself has not its own structures of Theme, information or cohesion. The passive voice is a marked syntactic structure, and the changing of active voice to passive voice is not a process of rankshift. The change from Actor in active voice to Agent in passive voice and the change from Goal to Medium both take place at the semantic level, with no rankshift or transcategorization at the lexicogrammatical level, hence no grammatical metaphor occurring. The ellipsis of the definite article in (12) can make the statement vague and difficult to interpret, but ellipsis itself is not grammatical metaphor.

According to Lassen (2003), (13a) is textual metaphor because a non-finite clause may have multiple possible interpretations. However, multiple interpretations can only show that such a structure may be ambiguous in meaning, which is not a process of generating grammatical metaphor. The ellipsis of the verb is in (14) will not cause difficulty in interpretation, but this kind of ellipsis is syntactically unacceptable. Ellipsis is a device of textual cohesion discussed by Halliday and Hasan (1976), which is a linguistic device to avoid repetition. However, Ellipsis itself will not cause the occurrence of grammatical metaphor.

\section{Textual Metaphor: A Non-finite Clause Perspective}

The types of textual metaphor mentioned above from various perspectives are actually representations of ideational and interpersonal metaphors in text, some of which are not even grammatical metaphors. "As a consequence, there is no need to include 'textual metaphor' as a separate term” (Yang, 2003: p. 127).

Grammatical metaphors are the result of rankshift or transcategorizaton, and the process of rankshifting and transcategorizing is at the same time a semogenic process which is referred to as semantic blend, semantic fusion or semantic junction (Halliday and Matthiessen, 1999: pp. 243-259) and "has a feedback effect into the semantics" (Ravelli, 1988: p. 137). "All such junctional elements involve grammatical metaphor” (Halliday and Matthiessen, 1999: p. 243). Semantic junction "enables the key defining motif of grammatical metaphor to be captured" (Ravelli, 2003) and is "a notion that is at the root of grammatical metaphor” (Lassen, 2003: p. 34). For example, although a nominalized verb construes a Thing, it still realizes a Process. Thus, nominalization is characterized with double functions, i.e., Process and Thing. Therefore, "double function is the identifying principle of grammatical metaphor" (Fan, 2007).

Non-finite clauses and finite clauses usually constitute clause complexes. When discussing relations between clauses, Halliday proposes two dimensions: interdependency and logicosemantic relation. The former consists of two relations, i.e. parataxis and hypotaxis, and the latter, expansion and projection. In expansion, the secondary clause expands the primary clause by elaborating, extending or enhancing. In projection, the secondary clause is projected through the primary clause, which instates it as a locution or an idea. The logico-semantic relation between clauses in clause complexes is mainly determined by conjunctions (Yang, 2003: p. 78). Halliday and Matthiessen (1999: p. 177) recognize a category of element, the relator, which is construed by conjunctions or conjunction groups. The relation between a finite clause and a non-finite clause in a clause complex tends to be extension and enhancement rather than elaboration, because "the relators themselves embody meanings of extension or enhancement” (Yang, 2003: p. 79). When there is not a conjunction functioning relator, the logico-semantic relation is usually construed by the non-finite element. Thus, the non-finite element has double functions, relator and process. Under this circumstance, the logico-semantic relation is usually of elaboration or enhancement and of additive and adversative extension. In other words, the realization of extension requires a conjunction or a preposition, which further indicates that extension is dependent upon relators. Conjunctions operate outside the rank scale, so they have no other functions except realizing relators. Non-finite verbs realizing relators will not change the logico-semantic relation between clauses, nor will rankshift which is required by ideational metaphor occur. This kind of double function only occurs in textual organization, hence textual metaphor. Here is an example:

(17) a. I worked for a local firm at that time, selling office equipment.

b. Instead of finding the perpetrators, they criminally charged the Earth First!

c. We used to go away at the weekend, taking all our gear with us.

d. You won't get away without the work being completed.

e. While pondering which way to go, I completely lost my bearings.

(17a) is an elaborating clause complex, non-finite element selling in which realizes both relator and process, which can be considered as the first type of textual metaphor from a nonfinite clause perspective. (17b) is an extending clause complex of the variation type, conjunctive preposition phrase instead of can not be omitted and the non-finite element finding has no double functions, hence no textual metaphor. (17c) construes the additive extension without conjunction or conjunctive preposition, and the non-finite element taking realizes both the relator and the process. (17d) and (17e) construe enhancement, and they will change into (17f) and $(17 \mathrm{~g})$ with the conjunctions omitted, and the non-finite element realizes both relator and process. Therefore, (17f) and (17g) are the textual metaphors of (17d) and (17e) respectively. These extending and enhancing non-finite clauses without explicit relators are the second type of textual metaphor from a non-finite clause perspective.

(17) f. You won't get away the work not being completed.

g. Pondering which way to go, I completely lost my bearings.

There are also such textual metaphors in non-finite -ed clauses. For example, (18b) is a textual metaphor of (18a):

(18) a. After Interviewed, Disxon made a statement.

b. Interviewed, Disxon made a statement.

Relators are usually realized by conjunctions or conjunctive groups linking two items at the same linguistic level, such as words, phrases/groups and clauses. However, when a finite clause and a non-finite clause are linked to form a clause complex, prepositions can also function as relators. For example:

(19) a. When you become a member, you will receive a membership card and a badge. 
b. When becoming a member, you will receive a membership card and a badge.

c. On becoming a member, you will receive a membership card and a badge.

In (19c), the preposition on realizes relator, functioning the same as the conjunction when. The former is of double functions and the latter not. For example, we can say on your becoming, but not when your becoming, and when you become in (19a) can not be changed into on you become. Accordingly, in (17b), although the conjunction group instead of functioning substitutive extension can not be omitted, non-finite element finding is not of double function. However, preposition phrase instead of realizing relator is of double functions. In this sense, (17d) is also textual metaphor with preposition phrase realizing relator. These extending and enhancing non-finite clauses with preposition phrases realizing relators are the third type of textual metaphor from a non-finite clause perspective.

The theory of cline in SFL has important implications to the research of textual metaphor from the non-finite clause perspective. According to SFL, there is not a distinct boundary between categories, and the members of two categories form a gradually graded continuum (Yang, 2007). For example, nonfinite clauses and preposition phrases form a cline.

(20) a. Looking at the picture, I couldn't help missing my middle school days.

b. Weather permitting, they will go on an outing to the beach tomorrow.

c. Considering the distance, he arrived very quickly.

d. During the war, people suffered food shortages.

e. At the news, he could hardly say a word.

Verbs tend to be grammaticalized into prepositions, which can be verified in both Chinese and English. For example, words like yan (沿), jiang (将) and pin (凭) in Chinese and considering, regarding, and concerning in English are all the result of prepositionalization. Verbs require participants more than prepositions do. Looking in (20a) and permitting in (20b) are the strongest in action and require logical subjects most among these example sentences. During in (20d) and at in (20e) are the weakest in action and have the least requirement of logical subjects. Considering in (20c) lies in between non-finite verbs and prepositions and relatively weak in action; it is an internal mental activity and has no external relations with the subject of the clause. In this sense, considering has double functions in the process of prepositionalization of verbs, hence textual metaphor. The enhancing non-finite clauses with prepositionalized non-finite verbs are the fourth type of textual metaphor from the non-finite clause perspective. Preposition at in (20e) is a core member of the category of prepositions and it has no double functions. Preposition during in (20d) evolved from ancient French verb durer, it was loaned to English in the middle ages, with the present participle form duren. And now, this word has completely prepositionalized and should not be treated as textual metaphor.

\section{Conclusion}

The occurrence of ideational metaphor and interpersonal metaphor is a semogenic rankshift or transcategorization. This is marked by qualitative changes in language form with double functions. As a second-order meaning mode, textual metafunction can be organized in a conventional or an unconventional way. The conventional organization is unmarked, and the un- conventional organization is marked. The marked structure functions emphasize and cohere rhetorically or pragmatically, but do not meet the conditions to create grammatical metaphor. The occurrence of ideational and interpersonal metaphors in textual circumstances provides these metaphors with textual effect, but it does not qualitatively change the organization of text. Based on the double functional identification principle, this paper proposed four types of textual metaphor from the non-finite clause perspective, i.e., elaborative non-finite clauses, extensive and enhancing non-finite clauses without relators, extensive and enhancing non-finite clauses with prepositions as relators and enhancing non-finite clauses with prepositionalized non-finite verbs.

\section{REFERENCES}

Derewianka, B. (2003). Grammatical metaphor in the transition to adolescence. In: A.-M. Simon-Vandenbergen, M. Taverniers, \& L. J. Ravelli (Eds.), Grammatical metaphor: Views from systemic functional linguistics (pp. 185-219). Philadelphia, PA/Amsterdam: John Benjamins.

Fan, W.-F. (2001). Theoretical study of grammatical metaphor. Beijing: Foreign Language Teaching and Research Press.

Fan, W.-F. (2007). A comprehensive pattern of grammatical metaphor. Foreign Language Education, 4, 12-15.

Goatly, A. (1996). Green grammar and grammatical metaphor. Journal of Pragmatics, 25, 537-560. http://dx.doi.org/10.1016/0378-2166(95)00057-7

Halliday, M. A. K. (1978). Language as social semiotic: The social interpretation of language and meaning. London: Edward Arnold.

Halliday, M. A. K. (1985). An introduction to functional grammar. London: Edward Arnold.

Halliday, M. A. K. (1994). An introduction to functional grammar (2nd ed.). London: Edward Arnold.

Halliday, M. A. K., \& Hasan, R. (1976). Cohesion in English. London: Longman Group.

Halliday, M. A. K., \& James, Z. L. (2005). A Quantitative study of polarity and primary tense in the English finite clause. In M. A. K. Halliday, \& J. J. Webster (Eds.), Computational and quantitative studies (pp. 93-129). London: Continuum.

Halliday, M. A. K., \& Matthiessen, C. (1999). Construing experience through meaning: A language-based approach to cognition. London/ New York: Cassell.

Halliday, M. A. K., \& Matthiessen, C. (2004). An introduction to functional grammar (3rd ed.). London: Edward Arnold.

Hu, Z.-L. (1996). Grammatical metaphor. Foreign Language Teaching and Research, 4, 1-7.

Huang, G.-W. (2002). Cleft sentences as grammatical metaphors. In G.-W. Huang, \& Z.-Y. Wang (Eds.), Discourse and language functions (pp. 32-41). Beijing: Foreign Language Teaching and Research Press.

Huang, G.-W. (2009). The analysis of grammatical metaphor in translation studies. Chinese Translators Journal, 1, 1-5.

Lassen, I. (2003). Accessibility and acceptability in technical manuals: A survey of style and grammatical metaphor. Philadelphia, PA/Amsterdam: John Benjamins,.

Liu, C.-Y. (2003). The stylistic value of grammatical metaphor. Modern Foreign Languages, 2, 120-127.

Liu, C.-Y. (2005). The reverse direction of rankshift between ideational metaphor and interpersonal metaphor. Foreign Language Teaching and Research, 5, 289-293.

Martin, J. R. (1992). English text: System and structure. Philadelphia, PA/Amsterdam: John Benjamins.

Martin, J. R. (1993). Life as a noun: Arresting the universe in science and humanities. In M. A. K. Halliday, \& J. R. Martin (Eds.), Writing science, literary and discourse power (pp. 241-293). London: Palmer Press.

Martin, J. R. (1997). Analyzing genre: Functional parameters. In F. 
Christie, \& J. Martin (Eds.), Genres and institutions (pp. 3-39). London: Cassell.

Ravelli, L. J. (1988). Grammatical metaphor: An initial analysis. In: E. H. Steiner, \& R. Veltman (Eds.), Pragmatics, discourse and text: Some systemically-oriented approaches (pp. 133-147). London: Pinter.

Ravelli, L. J. (2003). Renewal of connection: Integrating theory and practice in an understanding of grammatical metaphor. In A.-M. Simon-Vandenbergen, M. Taverniers, \& L. J. Ravelli (Eds.), Grammatical metaphor: Views from systemic functional linguistics (pp. 37-64). Philadelphia, PA/Amsterdam: John Benjamins.
Taverniers, M. (2006). Grammatical metaphor and lexical metaphor: Different perspective on semantic variation. Neophilologus, 2, 321332. http://dx.doi.org/10.1007/s11061-005-0531-y

Thompson, G. (1996). Introducing functional grammar. London: Edward Arnold.

Yang, B.-J. (2003). A study of non-finite clauses in English: A systemic functional approach. Beijing: Foreign Language Teaching and Research Press.

Yang, B.-J. (2007). Realization and meaning of cline in non-finite clauses. Foreign Language Research, 3, 50-54. 